\title{
New Fuels Urgently Needed
}

Dear Reader,

If you were to read the large number of not particularly well-informed reports in the press and on radio and television, you would doubtless be assuming that we are already seeing the beginning of the end of the "dirty" combustion engine. The hype about electric cars seems to be unending and the general message is that we could make even faster progress if the manufacturers and local authorities were able to put the necessary systems in place more quickly.

The question we need to be asking ourselves at this point is not whether the range of electric cars meets consumers' requirements, whether the electricity grid can cope with the demand, whether an electric motorway from the North Sea to Bavaria in Germany makes sense or whether the new digitisation act in Germany, which specifically excludes mobility up to the end of 2020 and therefore prevents the development of a smart grid, has come at the right time. We should not be focusing on electric transport, despite the fact that this is the right solution for the future.

Instead we should be looking at the combustion engine, which is currently being demonised, because cars powered by these engines will continue to play a dominant role over the coming four decades in many parts of the world. In addition, in the emerging and developing countries, the level of electrification will steadily fall. It is important to mention in this context that new cars have achieved levels of $\mathrm{CO}_{2}, \mathrm{NO}_{\mathrm{x}}$ and particle emissions that can be described as excellent. But the developers are now reaching the limits of what is currently possible and these limits are being determined by the available fuels.
We are running our modern combustionengine-powered cars on ancient fossil fuels that are primarily responsible for current emission levels. The majority of synthetic fuels, which offer significant advantages, are still in the development phase, although some are ready for market launch. However, there is little prospect of these products being available at our filling stations at affordable prices in the near future. There is no obvious evidence of thresholds being imposed on the oil industry similar to those that apply to the automotive industry. It would make a great deal of sense to require a growing proportion of synthetic fuels to be included in the total volume of fuel sold each year. From a systemic perspective, this would be the fastest way of bringing about a permanent reduction in emissions throughout the world and it would also represent a genuinely farsighted approach to environmental policy.

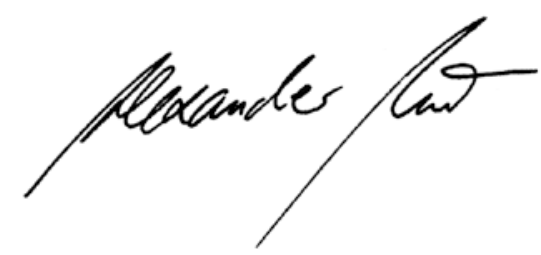

Dr. Alexander Heintzel Editor in Chief

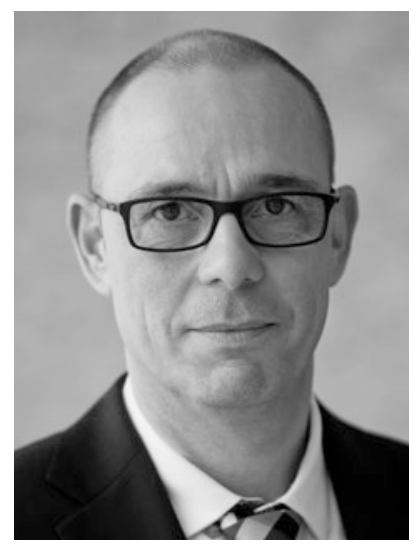

